INDO GLOBAL JOURNAL OF

PHARMACEUTICAL SCIENCES

ISSN 2249- 1023

\title{
Effect of Water Management on Methane Emission from a Rice Soils
}

\author{
Sandeep K. Malyan ${ }^{1 *}$, Arti Bhatia ${ }^{1}$, Om Kumar ${ }^{1}$, Joni Kumar ${ }^{2}$ \\ ${ }^{1}$ Centre for Environmental Sciences and Climate Resilient Agriculture, Indian Agricultural Research Institute, New Delhi 110012, India \\ ${ }^{2}$ Division of Entomology, Indian Agricultural Research Institute, New Delhi 110012, India
}

Address for Correspondance: Sandeep K. Malyan, Sandeepkmalyan@gmail.com

\section{Keywords}

Methane; Rice;

Water

Management;

Midseason

Drainage; Alternate

Wetting and

Drying.

\begin{abstract}
Methane is the second most potent green house gas after carbon dioxide and it is positively correlated with global warming. Globally methane contributes about $16 \%$ of the total anthropogenic emissions and rice cultivation alone contributes $10 \%$ of total anthropogenic methane emission at global level. Rice is the staple food for more than half of world's population and it is considered as a water demanding cereal. Standing water creates anaerobic conditions in rice which enhance methane emission from rice soils. However, appropriate water management practice may reduce the methane emissions from rice soils. A study was conducted with three water management practices: continuously flooding (CF), mid season drainage (MD) and alternate wetting and drying (AWD) to evaluate their effect on methane emission. Cumulative methane flux was highest in CF and lowest in MD. Water rmanagement practices such as MD and AWD improve soil redox potential which suppresses methanogenesis that results in methane emissions reduction from soil. Therefore, it can be concluded that water management practices such as MD and AWD were effective tools in reducing methane emission from rice soil. (C) 2016 iGlobal Research and Publishing Foundation. All rights reserved.
\end{abstract}

Conference Proceedings: International Conference on Advances in Plant and Microbial Biotechnology (PMB2017); JIIT, Noida: February 02-04, 2017

Indo Global Journal of Pharmaceutical Sciences( ISSN 22491023 ; CODEN- IGJPAI; NLM ID: 101610675) indexed and abstracted in EMBASE(Elsevier), SCIRUS(Elsevier),CABI, CAB Abstracts, Chemical Abstract Services(CAS), American Chemical Society(ACS), Index Copernicus, EBSCO, DOAJ, Google Scholar and many more. For further details, visit http://iglobaljournal.com 